\title{
A cross sectional epidemiological survey of shipyard workers exposed to hand-arm vibration
}

\author{
Richard Letz, Martin G Cherniack, Fredric Gerr, Dawn Hershman, Patricia Pace
}

\begin{abstract}
The hand-arm vibration syndrome, widely known as vibration white finger, is a disorder of nerves and blood vessels that occurs in workers exposed to segmental vibration. A cross sectional symptom survey was performed on a sample of workers employed by a large shipyard in the north eastern United States. Random samples were drawn from departments composed of full time dedicated pneumatic grinders, workers with part time exposure to vibration, and other workers not exposed to vibratory tools. Of the 375 workers sampled, $79 \%$ responded. The prevalence of white finger symptoms was $71 \%, 33 \%$, and $6 \%$ among the three exposure groups respectively. Similarly, the prevalence of numbness and tingling in the hands and fingers in the three exposure groups was $84 \%, 50 \%$, and $17 \%$. Workers were classified according to the Stockholm Workshop staging systems for vascular and sensorineural symptom severity. Exposure-response analyses of both vascular and sensorineural stage showed monotonically increasing prevalence of higher disease stages with increasing duration of exposure. Logistic regression analysis, performed to control for potential confounding factors including age and current smoking state, produced highly significant $(p<0.001)$ associations between cumulative duration of exposure and prevalence of symptoms. In these analyses smoking state was significantly related to vascular and sensorineural symptoms and age was not. Average latency to onset of symptoms was less than five years of full time equivalent work with vibratory tools. Logistic regression analyses were performed to assess the effect of use of particular work practices on reported
\end{abstract}

Division of Environmental and Occupational Medicine, Mount Sinai School of Medicine, New York, New York, USA

R Letz, F Gerr, D Hershman

Occupational Medicine Program, Yale University School of Medicine, New Haven, Connecticut, USA M G Cherniack, P Pace symptoms. Further study of this workforce with objective, quantitative measures of peripheral neurological and vascular function is required to characterise the clinical and subclinical effects of vibration exposure.

The hand-arm vibration syndrome (HAVS) is characterised by both vascular and neurological abnormalities. ${ }^{12}$ The most clinically apparent pathology is cold induced vasospasm resulting in whitening or loss of colour in the fingers and hands. This vascular abnormality is a form of secondary Raynaud's phenomenon, commonly referred to as "vibration white finger." The neurological component manifests as pain and paraesthesias suggestive of peripheral neuropathy or focal compression, a quantifiable deficit of cutaneous sensory performance, and a complex pattern of loss of forearm and hand strength with early fatigue. ${ }^{1}$

The clinical sequelae of vibration exposure were observed more than 70 years ago in the United States and Italy. ${ }^{34}$ During the past 20 years more than 50 cross sectional studies of vibration exposed workers have been published. A high prevalence of symptoms associated with exposure to vibration has been seen in workers using gasoline powered chain saws, rock drills, grinders, riveters, and jackhammers. ${ }^{5}$ Four longitudinal studies, all of chainsaw operators, have been conducted in the United Kingdom, ${ }^{6}$ Finland, ${ }^{7}$ Japan, ${ }^{8}$ and Canada. ${ }^{9}$ Nevertheless, much remains unknown about the pathophysiology, characteristics of the critical exposure, and quantitative assessment of a disease with one of the highest attack rates in the contemporary occupational setting. Accordingly, particular reliance has been placed on symptom reporting as the basis for staging of disease and on epidemiological associations with occupation to identify workers at high risk. Many of the recent published reports have referred to the TaylorPelmear classification system, a semiquantitative assessment of functional interference with work and social activities caused by progressive vibration related symptoms. ${ }^{10}$ Clinical stages are heavily weighted towards visualised vascular changes, and do not provide an independent classification of the sensorineural components of HAVS. 
Table 1 Stockholm workshop staging systems

Vascular stages

0 No attacks

1 Occasional attacks affecting only the tips of one or more fingers

2 Occasional attacks affecting distal and middle (rarely also proximal) phalanges on one or more fingers

3 Frequent attacks affecting all phalanges of most fingers

4 As in stage 3, with trophic skin changes in the finger tips

Sensorineural stages

0 No symptoms

1 Intermittent numbness, with or without tingling

2 Intermittent or persistent numbness, reduced sensory perception

3 Intermittent or persistent numbness, reduced tactile discrimination and/or manipulative dexterity

Based on the recognition that the sensorineural and vascular symptoms can develop separately, a revised consensus system for staging severity of disease, the Stockholm Workshop scale, was introduced in $1986 .{ }^{112}$ The revised scales no longer use social and occupational consequences of disease as staging criteria; instead they rely exclusively on a symptom grade. Classification of a set of subjects with both the Stockholm Workshop scale and the TaylorPelmear scale indicated a high degree of concordance for the most severely affected with poorer correspondence between the lower stages. ${ }^{11}$ The Stockholm Workshop scale has assumed particular importance in the United States, as the National Institute for Occupational Safety and Health (NIOSH) has recently recommended its adoption as the basis for worker protection, including mandatory and fully compensated work removal for stage 2 sensorineural or peripheral vascular symptoms. ${ }^{2}$ Table 1 summarises the Stockholm Workshop scale.

One recent epidemiological study of HAVS has employed the Stockholm Workshop scale to stage vascular disease among 89 machinery platers in Sweden. ${ }^{13}$ No large scale epidemiological studies of HAVS utilising the Stockholm Workshop scales of both vascular and neurological disease severity have been published. Interestingly, no epidemiological studies of HAVS have been reported at all in the United States, except for the extensive shipyard and foundry survey conducted by NIOSH more than a decade ago. ${ }^{14}$ In the current study, the Stockholm Workshop scale provided the basis for disease classification used in exposure-response analyses of a large sample of workers exposed to vibratory tools.

The initial impetus for performing the present study came from clinical evaluation of patients with upper extremity complaints at a university sponsored occupational medicine clinic. These patients were employed at a nearby shipyard, most of them as dedicated chippers and grinders using pneumatic tools for more than four hours a day. About 18000 workers are engaged in the construction of nuclear powered ships at the yard. In the first step of a comprehensive evaluation of potential disease related to vibration exposure among these workers, 48 patients who sought treatment at the occupational medicine clinic and had exposure to pneumatic tools at the shipyard were evaluated clinically according to protocol. ${ }^{15}$ This clinical series showed a high prevalence of symptoms and abnormal test results. Specifically, nearly all cases $(98 \%)$ reported numbness and tingling and vasospasm (white finger) was described by $88 \%$. Vibrotactile thresholds and hand strength dynamometry were the best of a number of clinical, functional, and electrophysiological tests at discriminating the most symptomatic and least symptomatic of these patients. This case series was not suitable for providing information on the prevalence of the problem in the shipyard population. The current investigation was undertaken to provide such information and to relate the severity of symptoms to various exposure indices.

Unique to this shipyard is the organisation of labour around dedicated craft duties, which results in uniformity of work performed within a given department. This situation is ideal for the study of work related diseases, as all members of a given department tend to have similar exposures. Also, three independent studies of pneumatic tools used at this shipyard have been conducted, although only one is available as an open publication. ${ }^{16}$ Therefore, a cross sectional survey was conducted on a sample of the active work force at the shipyard to estimate the overall prevalence of symptoms and any relation of symptoms with job title, work tenure, cumulative vibratory tool use, and use of specific types of vibratory tools.

\section{Methods}

SUBJECTS

Workers, all designated as boilermakers, were selected from 15 departments. Within departments potential participants were chosen randomly from payroll records provided by the shipyard management. Departments designated as non-exposed were shipriggers, crane operators, dock technicians and bargemen, electrical and welding inspectors, and maintenance welders. Those designated as partially exposed were welders, loftsmen, tool attendants, shipfitters, lead bonders, pipe welders, and drillers. Chippers and grinders were defined as full time pneumatic tool users. The sampling ratio was 1 of 3 for dedicated pneumatic tool users and 1 of 10 for other departments. This sampling strategy was utilised to ensure inclusion of workers with a wide range of exposures to vibratory tools while also ensuring that a large number of the most exposed were included.

QUESTIONNAIRE

A questionnaire was developed for self administra- 
tion based, in part, on the work of Brubaker et $a l^{9}$ and Brammer et al. ${ }^{17}$ Questions were included to obtain information about demographics, vibration exposure including frequency and duration of use of various types of tools, vascular and neurological symptoms, and potential confounders such as alcohol consumption, use of tobacco, and past medical conditions. To identify white finger, subjects were asked if either presently or in the past any parts of their fingers or hands turned white or lost colour in the cold. If the subject responded affirmatively, questions as to the duration, frequency, anatomic location, and seasonal differences of their symptoms followed. To identify neurological abnormality, the subject responded to a question about experiencing symptoms of numbness either with or without tingling (pins and needles) in the fingers or hands. Again, if the subject responded affirmatively, further questions were asked to evaluate the severity and duration of the neurological symptoms. Also, questions were asked to assess loss of hand function, focussing on the ability to manipulate and grip objects or perform activities that require dexterity. These questions were used to classify all participants according to the Stockholm Workshop sensorineural and vascular staging systems (table 1). A list of the 13 most commonly used pneumatic tools was also included in the questionnaire, and the subject was asked to report the number of hours per week and the total number of years spent using each tool. The list was based on tool room records. From this information a cumulative total number of hours was calculated for each type of tool for each exposed subject. The questionnaire consisted of 58 questions and an area for comments on the last page. It was pilot tested among shop stewards before administration to assess whether questions and explanatory statements were adequate to ensure appropriate self administration.

In March of 1988 questionnaires were distributed by union officials to all workers identified by the randomisation protocol. Informed consent in accordance with institutional guidelines was obtained from each participant. The questionnaires were self administered and returned directly to the occupational medicine clinic in sealed envelopes. After the questionnaires were collected, identification numbers were assigned to each page, and the first page of demographic information was removed and stored separately. This procedure ensured confidentiality when the questionnaires were evaluated. The questionnaire information was entered manually into a Compaq Plus personal computer.

Questionnaires were considered incomplete if information was missing on age, smoking state, duration of exposure, use of specific types of tool, basic vascular symptoms, or basic neurological symptoms. Also, all respondents who reported a diagnosis of thoracic outlet syndrome, peripheral neuropathy, diabetes, or rheumatoid arthritis were excluded from the analysis, as these conditions independently affect the symptom outcomes of interest.

\section{EXPOSURE MEASUREMENTS}

In 1987 and 1988, three independent studies of pneumatic tools at the shipyard were conducted. Two of the studies were privately funded proprietary investigation $\mathrm{s}^{18}{ }^{19}$ and the third study was undertaken by NIOSH. ${ }^{16}$ Measurements were made in a similar manner and on comparable equipment in the three studies, as specified by the American National Standard Institute (ANSI) guide for the measurement and evaluation of human exposure to vibration. ${ }^{20}$ The vibration spectrum was analysed in one third octave bands in three orthogonal directions- $x, y$, and $z-$ and expressed as $\mathrm{m} / \mathrm{sec}^{2}$. Despite these similarities in methods, there were also some important differences. The accelerometers were attached directly to the tools in the Whitaker ${ }^{19}$ and NIOSH ${ }^{16}$ studies, whereas they were attached to the glove of the hand holding the tool in the Ungar study..$^{18}$ The NIOSH study took place at the actual work site, assessing routine operations. The two proprietary studies were done in controlled or simulated settings where sur-

Table 2 Measurements of vibration intensity for various types of tools in three studies at the shipyard

\begin{tabular}{|c|c|c|c|c|c|}
\hline \multirow[b]{2}{*}{ Tool } & \multirow[b]{2}{*}{ Department } & \multirow[b]{2}{*}{$R P M$} & \multicolumn{3}{|c|}{ Weighted (unweighted) accelerations } \\
\hline & & & $U N G A R$ & $B T I$ & NIOSH \\
\hline Chipping hammer & CG, LB & - & $5 \cdot 5$ & - & $70 \cdot 8(159 \cdot 9)$ \\
\hline $\begin{array}{l}\text { Large grinder: } \\
\text { Tool No } 1\end{array}$ & $\begin{array}{l}\text { CG, WLD, } \\
\text { SHP }\end{array}$ & 6000 & $2 \cdot 1$ & $2 \cdot 3(46 \cdot 7)$ & $\begin{array}{l}9.8(312.8) \\
7.6(89 \cdot 6)^{\star}\end{array}$ \\
\hline Tool No 2 & CG & 6000 & $5 \cdot 6$ & $2 \cdot 7(32 \cdot 1)$ & $\begin{array}{l}8.9(52.6) \\
7.6(24.8)^{\star}\end{array}$ \\
\hline $\begin{array}{l}\text { Large burr } \\
\text { Small burr } \\
\text { Offset burr } \\
\text { Offset wheel }\end{array}$ & $\begin{array}{l}\text { CG, LB, WLD, SHT, SHP } \\
\text { CS, WLD, SHP } \\
\text { CS, WLD } \\
\text { CG, WLD }\end{array}$ & $\begin{array}{l}25000 \\
25000 \\
18000 \\
14000\end{array}$ & $\begin{array}{l}2 \cdot 7 \\
5 \cdot 4 \\
3 \cdot 1 \\
3 \cdot 4\end{array}$ & $\begin{array}{l}4 \cdot 5(94 \cdot 2) \\
6 \cdot 3(157 \cdot 7) \\
8 \cdot 0(210 \cdot 0) \\
-\end{array}$ & $\begin{array}{c}17 \cdot 5(183 \cdot 3) \\
34 \cdot 7(244 \cdot 5) \\
47 \cdot 8(213 \cdot 4) \\
5 \cdot 2(63 \cdot 6)\end{array}$ \\
\hline
\end{tabular}

CG = Chipper/grinder; WLD = structural welder; LB = lead border; SHP = shipfitter; SHT = sheet metal worker.

* Measurement with same tool while performing a different job. 
faces and "jobs" could be more quantitatively defined.

In all, 51 pneumatic tools used in the shipyard were measured, although applications are infrequent for many of them. Mean tool age varied from less than a year to 20 years. The two principal categories measured were grinding tools and burring tools, although tool weight and measured acceleration varied significantly within each of these categories. Thirteen different tools were tested in the Ungar study, 21 in the Whitaker study, and 11 in the NIOSH study. Table 2 presents the comparative accelerations from three studies. The six tools listed in table 2 were selected for comparison because of overlapping data from the three surveys and because of extensive use as identified through the questionnaire survey. All values are presented as a simple mean from the axis with the highest recorded acceleration levels. In all three studies accelerations were weighted for each one third octave band, in a manner prescribed in the ANSI Standard, to determine a cumulative weighted vibration exposure. For the Whitaker and NIOSH data, results are also presented in an unweighted format, consistent with current NIOSH recommendations. ${ }^{2}$

Comparisons are difficult, both because of intrinsic differences between the applied and the controlled setting and because of the poor correspondence between unweighted and weighted acceleration values. Particularly for the NIOSH study, significant variations existed between individual trials or runs on the same tool. In perhaps the most extreme case, for the chipping hammer, weighted accelerations in the $Z$, or dominant, axis varied from $22 \cdot 7-187 \cdot 7 \mathrm{~m} /$ $\mathrm{sec}^{2}$ and unweighted accelerations varied from $117 \cdot 6$ $278.9 \mathrm{~m} / \mathrm{sec}^{2}$. The extreme variability between acceleration measures found on the same tools in different studies and even within studies, as well as the lack of acceleration measures on all types of tools used, precluded combining of these measures with the reported number of hours of exposure to each type of tool to produce a cumulative acceleration exposure index for each study participant.

\section{STATISTICAL ANALYSIS}

Analyses were performed with the Statistical Analysis System ${ }^{21}$ and PROC LOGIST ${ }^{22}$ was used to perform polychotomous logistic regression analyses. Because distributions of exposure times were extremely skewed to the right, regression analyses were performed with the common logarithms of the exposure times as well as with their untransformed values.

\section{Results}

Of the 375 questionnaires distributed, 297 were returned for an overall response rate of $79 \%$. The
Table 3 Exclusions by vibration exposure group

\begin{tabular}{|c|c|c|c|}
\hline & \multicolumn{3}{|c|}{ Vibration exposure group } \\
\hline & None & Part time & Full time \\
\hline Incomplete questionnaire & 2 & 6 & 6 \\
\hline $\begin{array}{l}\text { Diagnosis of thoracic outlet } \\
\text { syndrome }\end{array}$ & 1 & 1 & 1 \\
\hline $\begin{array}{l}\text { Diagnosis of peripheral } \\
\text { neuropathy }\end{array}$ & 0 & 0 & $1^{\star}$ \\
\hline Diagnosis of diabetes & 0 & 0 & 3 \\
\hline Diagnosis of rheumatoid arthritis & 0 & 2 & $4^{\star}$ \\
\hline
\end{tabular}

*One subject reported diagnoses of both peripheral neuropathy and rheumatoid arthritis.

response rate was similar between the three a priori exposure groups, with a slightly lower response rate from the chipper/grinder department $(72 \%)$. Of the 297 questionnaires returned, data from 26 subjects $(8.8 \%)$ were not included in the statistical analyses due to their meeting a priori exclusion criteria. The largest number of excluded questionnaires (14) resulted from their not meeting a minimal criterion for completeness. Table 3 presents the numbers of subjects excluded for this and other reasons separately for each of the three exposure groups. The full time pneumatic tool users reported previous diagnosis of rheumatoid arthritis more frequently than the other two exposure groups. Of the 271 included in the data analyses, 53 were workers not exposed to vibratory tools (group 1), 115 were exposed to vibration part time (group 2), and 103 were full time dedicated pneumatic tool users (group 3).

Table 4 delineates demographic and exposure variables by exposure group. No age differences were found between groups. The sample was $86 \%$ white, $11 \%$ black, and $3 \%$ of other races. Black workers showed a trend toward greater representation, with greater vibratory tool use. Among exposed groups, smoking prevalence was highest among the most exposed workers, but the highest prevalence of smoking was seen in non-exposed workers. Daily tobacco consumption among those who smoked was comparable across exposure groups. A smaller percentage of the non-exposed subjects worked on the second shift than did exposed workers. One of five full time grinders reported using special anti-vibration gloves, whereas only two percent of part time exposed and none of the non-exposed workers used them. Half of the part time exposed and almost $90 \%$ of full time exposed workers worked more than five hours per week with their hands over their heads. The reported number of hours per week of vibratory tool use confirmed the large difference in current exposure among the three groups of departments. In this stable work force, age and duration of exposure were closely correlated $(r=0.58$ among exposed groups). 
Table 4 Demographic and exposure information for the three vibration exposure groups

\begin{tabular}{|c|c|c|c|}
\hline & \multicolumn{3}{|c|}{ Vibration exposure group } \\
\hline & None & Part time & Full time \\
\hline $\begin{array}{l}\text { Number of subjects } \\
\text { Age (mean) (SD) }\end{array}$ & $\begin{array}{l}53 \\
38 \cdot 5(10 \cdot 2)\end{array}$ & $\begin{array}{l}115 \\
36.5(9.5)\end{array}$ & $\begin{array}{l}103 \\
37 \cdot 4(11 \cdot 1)\end{array}$ \\
\hline $\begin{array}{l}\text { Ethnic origin }(\%) \text { : } \\
\text { White } \\
\text { Black } \\
\text { Other } \\
\text { Current smokers (\%) } \\
\text { Current smoking of those who smoke (mean No a day (SD)) }\end{array}$ & $\begin{array}{r}92.5 \\
3.8 \\
3.8 \\
58.5 \\
19.0(9 \cdot 6)\end{array}$ & $\begin{array}{l}89.6 \\
9.6 \\
0.9 \\
39 \cdot 1 \\
21 \cdot 7(10 \cdot 5)\end{array}$ & $\begin{array}{r}80 \cdot 4 \\
16 \cdot 7 \\
2 \cdot 9 \\
52 \cdot 4 \\
20 \cdot 0(18 \cdot 7)\end{array}$ \\
\hline $\begin{array}{l}\text { Current workshift: } \\
\text { Day }(\%) \\
\text { Evening }(\%) \\
\text { Anti-vibration glove use }(\%) \\
\text { Work }>5 \text { hours a week with hands over head } \\
\text { Current vibratory tool use (mean hours a week (SD)) } \\
\text { Duration of exposure to vibratory tools (mean years }(\text { SD)) } \\
\text { Cumulative exposure to vibratory tools (mean hours } \times 1000(\text { SD }) \text { ) }\end{array}$ & $\begin{array}{l}78 \cdot 8 \\
21 \cdot 1 \\
0 \cdot 0 \\
-0 \cdot 0(0 \cdot 0) \\
0 \cdot 0(0 \cdot 0) \\
0 \cdot 0(0 \cdot 0)\end{array}$ & $\begin{array}{l}65 \cdot 8 \\
34 \cdot 2 \\
2 \cdot 6 \\
53 \cdot 0 \\
14 \cdot 5(11 \cdot 9) \\
9 \cdot 1(7 \cdot 3) \\
6 \cdot 4(7 \cdot 1)\end{array}$ & $\begin{array}{l}63 \cdot 7 \\
36 \cdot 3 \\
22 \cdot 6 \\
87 \cdot 3 \\
34 \cdot 2(9 \cdot 2) \\
11 \cdot 3(7 \cdot 7) \\
19 \cdot 0(14 \cdot 7)\end{array}$ \\
\hline
\end{tabular}

Although many subjects (55\%) reported injuring their fingers, hands, arms or shoulders severely enough to require a doctor's care, the proportion of subjects reporting such injuries was not different among the three exposure groups. The full time pneumatic tool users reported previous diagnosis of Raynaud's phenomenon, carpal tunnel syndrome, and Dupuytren's contracture more frequently than the other two exposure groups.

Table 5 presents the proportion of workers in each exposure category reporting selected symptoms. Overall, a high rate of reporting of positive symptoms was seen among vibration exposed workers. Vascular symptoms were reported by $6 \%$ of the non-exposed, $33 \%$ of part time tool users, and $71 \%$ of grinders, and neurological symptoms were reported by $17 \%$ of non-exposed, $50 \%$ of part-time tool users, and $84 \%$ of grinders. These prevalences represent crude odds

Table 5 Symptoms by vibration exposure group

\begin{tabular}{|c|c|c|c|}
\hline & \multicolumn{3}{|c|}{ Vibration exposure group } \\
\hline & None & Part time & Full time \\
\hline No & 53 & 115 & 103 \\
\hline $\begin{array}{l}\text { Complaints ( } \% \text { yes): } \\
\text { White finger } \\
\text { Numbness and tingling } \\
\text { Sensory loss } \\
\text { Loss of dexterity } \\
\text { Difficulty manipulating } \\
\text { Dropping objects } \\
\text { Loss of grip strength }\end{array}$ & $\begin{array}{r}5 \cdot 7 \\
17 \cdot 0 \\
15 \cdot 1 \\
13 \cdot 2 \\
3.7 \\
5 \cdot 7 \\
15.4\end{array}$ & $\begin{array}{l}33.0 \\
50.4 \\
38.9 \\
38 \cdot 1 \\
32.4 \\
14.6 \\
42 \cdot 1\end{array}$ & $\begin{array}{l}70.9 \\
83.5 \\
75.5 \\
63.4 \\
55.4 \\
36.0 \\
66.3\end{array}$ \\
\hline $\begin{array}{l}\text { Vascular stage (\%): } \\
\text { Stage } 0 \\
\text { Stage } 1 \\
\text { Stage } 2 \\
\text { Stage } 3\end{array}$ & $\begin{array}{r}94.3 \\
0.0 \\
5.7 \\
0.0\end{array}$ & $\begin{array}{r}67.0 \\
9.6 \\
14.9 \\
8.7\end{array}$ & $\begin{array}{l}29 \cdot 1 \\
13 \cdot 6 \\
39 \cdot 4 \\
19 \cdot 4\end{array}$ \\
\hline $\begin{array}{l}\text { Sensorineural stage (\%): } \\
\text { Stage 0 } \\
\text { Stage } 1 \\
\text { Stage } 2 \\
\text { Stage } 3\end{array}$ & $\begin{array}{r}83.0 \\
3.8 \\
11.3 \\
1.9\end{array}$ & $\begin{array}{l}49 \cdot 6 \\
17 \cdot 4 \\
20 \cdot 9 \\
12 \cdot 2\end{array}$ & $\begin{array}{l}16.5 \\
13.6 \\
42 \cdot 7 \\
27 \cdot 2\end{array}$ \\
\hline
\end{tabular}

ratios of $7 \cdot 7$ and 38.6 for vascular symptoms among part time and full time pneumatic tool users respectively. The corresponding crude odds ratios were 4.9 and $25 \cdot 6$ for sensorineural symptoms.

\section{STOCKHOLM SCALE ANALYSES}

Table 5 also presents the results of classification of workers according to the peripheral vascular and sensorineural Stockholm Workshop scales for the three exposure groups. More workers were classified in the higher disease stages in the vibration exposed groups than in the non-exposed group, and more grinders were classified in the higher stages than part time exposed workers.

The concordance between vascular and sensorineural stages in these workers was also investigated. Table 6 presents a cross tabulation of application of these two staging scales. Many workers had similar severity of vascular and sensorineural symptoms, but some were classified at higher stages of one scale than the other. Severe sensorineural symptoms with slight or absent vascular symptoms were more prevalent than the converse.

\section{EXPOSURE RESPONSE ANALYSES}

Figure 1 summarises the results of reported hours of use of the 13 types of vibratory tools for the two exposed groups. Chippers/grinders had considerably more cumulative exposure with most of their

Table 6 Concordance between vascular and sensorineural staging

\begin{tabular}{lrrrrr}
\hline & \multicolumn{5}{c}{ Vascular stage } \\
\cline { 2 - 6 } & & \multicolumn{1}{c}{0} & 1 & \multicolumn{1}{c}{2} & 3 \\
\hline Sensorineural stage & 0 & 106 & 7 & 4 & 1 \\
& 1 & 21 & 6 & 9 & 0 \\
& 2 & 25 & 6 & 27 & 16 \\
& 3 & 5 & 6 & 19 & 13 \\
\hline
\end{tabular}




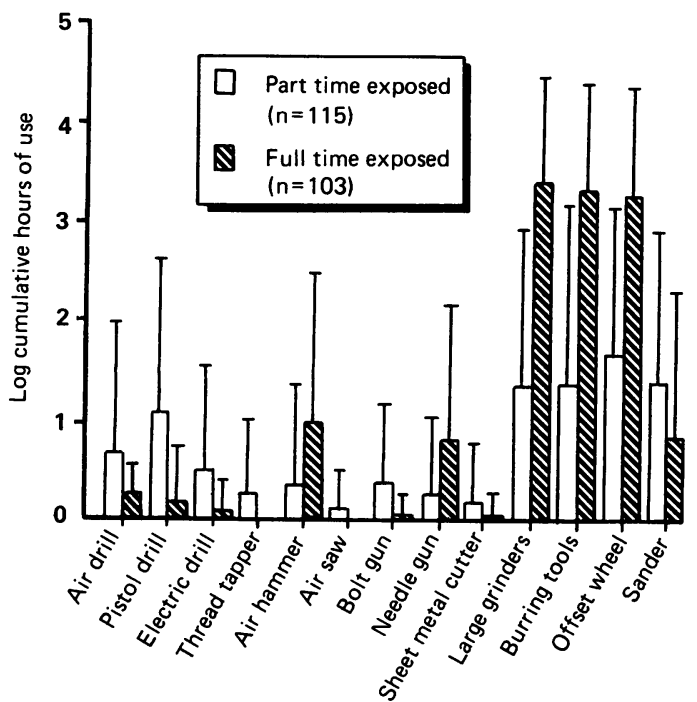

Figure 1 Mean (+1 SD) log cumulative use of various pneumatic tools by part time and full time vibratory tool users.

exposure being to large grinders, burring tools, and offset wheels. Part time exposed workers also used those three tool types for a substantial portion of their exposure time, and they used drills and sanders more than the chippers/grinders. Considerable variability occurred in cumulative vibratory tool use within groups.

For descriptive purposes, respondents were grouped into exposure categories on the basis of their reported cumulative number of hours of exposure to vibratory tools. Cut off points were selected to divide

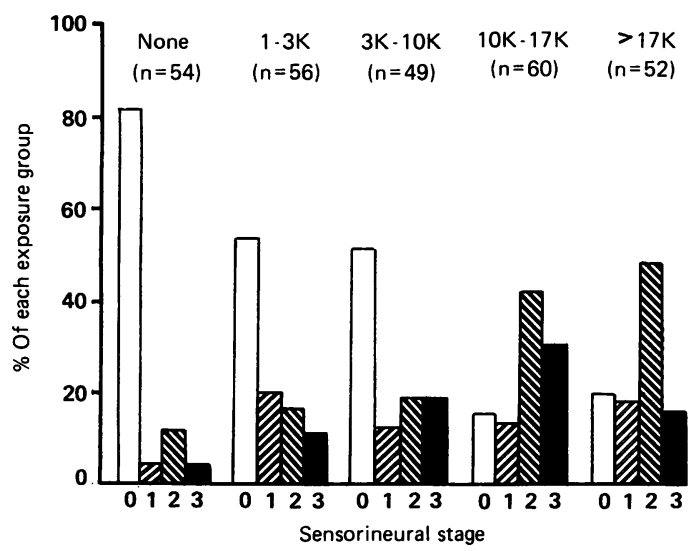

Figure 2 Per cent of shipyard workers in each of four Stockholm Workshop scale sensorineural stages with workers grouped according to thousands of hours of cumulative vibratory tool use.

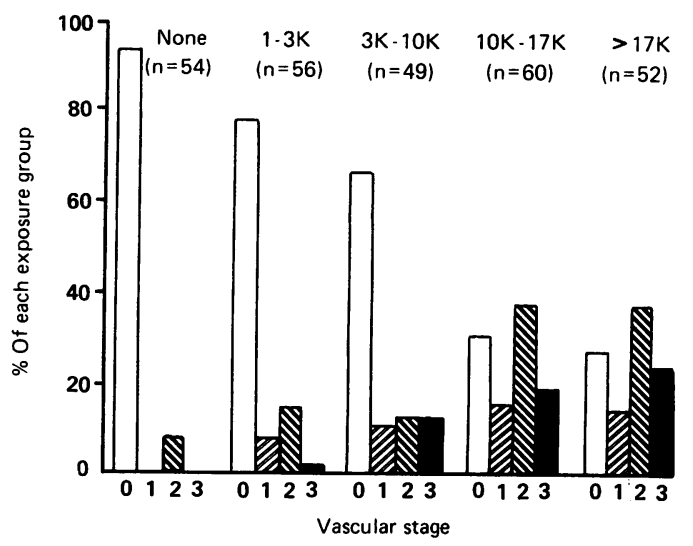

Figure 3 Per cent of shipyard workers in each of four Stockholm Workshop scale vascular stages with workers grouped according to thousands of hours of cumulative vibratory tool use.

participants into rough quintiles, as groups of the same size were desired and $20 \%$ had no exposure. The cut off points selected were $1,3000,10000$, and 17000 hours, which corresponded to none, $1 \cdot 5,5$, and 8.5 full time equivalent (FTE) years of vibratory tool use. Figure 2 presents the proportion of participants in each of the five cumulative vibration exposure groups classified into each sensorineural stage. Figure 3 presents the results of corresponding vascular classifications. The effect of cumulative exposure to vibratory tools is striking. For example, the proportion of workers classified as asymptomatic (SN-0) dropped monotonically from $82 \%$ in those not exposed to vibration to $19 \%$ in those with more than 17000 hours of cumulative exposure. The proportion of workers classified as stage 2 or 3 increased with increasing cumulative exposure for both sensorineural and vascular symptoms, with the one exception that the proportion of workers with more than 17000 hours of exposure classified as SN3 was somewhat lower than the next most exposed group. Interestingly, the effect of exposure was apparent even in those workers with less than 3000 hours of exposure. Specifically, when workers with up to 3000 hours of exposure were compared with non-exposed workers, relatively fewer were classified as $\mathrm{SN}-0(54 \% v 82 \%)$, and relatively more were classified in each of the higher stages. The median latency for appearance of symptoms of white finger was about 8400 hours of vibratory tool use and 8200 hours for numbness, slightly more than four years of full time use.

In the current sample age and duration of exposure were correlated ( $r=0.56$ for workers in the two exposed groups), and age is a potential covariate of many of the symptoms analysed. Although smoking was not strongly related to duration of exposure in our sample, it is also a potential covariate of outcome, 
particularly for vascular symptoms. Also, a trend was found towards over-representation of black workers in the most exposed group. Therefore, polychotomous logistic regression was employed to investigate the relation between exposure and both sensorineural and vascular stage while controlling the effects of age, smoking state, and race. In these analyses the outcome variable was either the four sensorineural stages or the four vascular stages, and the regressor variables were age, smoking state, an indicator variable for race, and one of the quantitative exposure variables (current number of hours of vibratory tool use, years of vibration exposure, cumulative number of hours of exposure, and the common logarithm of cumulative exposure). The estimated logistic regression parameters for vibration exposure variables were significantly different from zero $(p<0.0001)$ in all analyses. Models using the log transformed cumulative exposure variable produced the best fits to the data for both vascular and sensorineural outcome variables. When vascular stage was the polychotomous outcome variable, the estimated odds ratio (OR) was 2.9 (95\% confidence interval $(95 \% \mathrm{CI}) 1.7-5.0)$ for each log unit increase in total hours of vibratory tool use, and the corresponding estimated OR was 1.8 (95\% CI 1.2-2.9) when sensorineural stage was the outcome variable. There was a statistically significant effect of smoking state (estimated OR of $2.6 ; 95 \%$ CI $1.5-4.6$ for vascular stage and OR $1.9 ; 95 \%$ CI $1.1-3.2$ for sensorineural stage), but neither age nor race had a significant effect in any of the analyses. When quantitative smoking variables (the amount of current smoking, cumulative lifetime smoking, and common logarithm of cumulative lifetime smoking) were used instead of a dichotomous variable for current smoking state, no significant relations were found between smoking and either vascular or sensorineural stage.

Exploratory analyses were also performed in an attempt to identify specific work practices that were correlated with vascular or sensorineural stage. Only the 218 workers exposed to vibratory tools were included in these analyses. Variables in the polychotomous logistic regression models were age, current smoking state, race, log total hours of vibratory tool exposure, use of anti-vibration gloves, and an indicator variable for working more than five hours per week with hands above head height. Analyses employing variables for the cumulative number of hours of use of each of the 13 tool types were considered for inclusion, but the sampling strategy employed in the present study (that is, oversampling of grinders, who use vibratory tools for much of their work time and use only some types of tools) did not allow appropriate estimation of the associations between symptom categories and use of various tool types. Neither age nor race were significantly related to either sensorineural or vascular stage. Estimated effects for log total hours of vibratory tool exposure and current smoking state were essentially the same as those mentioned earlier for the analyses of the full study group. The variable for working with tools held above head height more than five hours per week was significantly related to symptom stage classifications, with estimated ORs of 3.3 $(95 \%$ CI $1 \cdot 8-6 \cdot 0)$ for sensorineural stage and $2 \cdot 2$ ( $95 \%$ CI $1 \cdot 1-4 \cdot 2)$ for classification of vascular stage. The proportion of those reporting that they worked more than five hours per week with hands above head height ranged from $50 \%$ of those classified as $\mathrm{SN}-0$ up to $90 \%$ of those classified as $\mathrm{SN}-3$. A trend was found for an association between the use of antivibration gloves and sensorineural stage, with an estimated OR of $2 \cdot 1(95 \%$ CI $0.98-4.7)$, but not vascular stage. Use of anti-vibration gloves was associated, however, with increased risk of having symptoms, which may have resulted from those experiencing symptoms having changed from regular work gloves to anti-vibration gloves.

\section{Discussion}

The major finding of this study was that a high proportion of shipyard workers with occupational exposure to upper extremity vibration reported experiencing vasospastic and sensorinueural symptoms. More than occasional numbness and tingling in the hands was reported with greater frequency than episodes of white finger. Reporting of symptoms was not significantly related to age but was highly related to several indices of duration of vibratory tool use. A substantial increase in prevalence of symptoms was seen in subjects with $\mathbf{3 0 0 0}$ hours of exposure compared with those without exposure. Further increases in symptom prevalence were observed in groups with 3000-10 000 and with 10000-17 000 hours of exposure; however, no further increases were seen in workers with more than 17000 hours of exposure.

The prevalence of vascular and sensorineural symptoms found in this population is among the highest reported in recent publications on vibration exposed workers. A high prevalence of HAVS has been seen in cross sectional studies of forestry workers $^{23}$ and rock drillers. ${ }^{24}$ The reported prevalence of HAVS among vibration exposed shipyard workers has varied greatly. Bovenzi et $a l^{25}$ reported a $79 \%$ prevalence of sensorineural symptoms and a $31 \%$ prevalence of vascular symptoms among 169 workers with an average duration of exposure of 7.3 years. Behrens et $a l^{14}$ found a prevalence of more than $45 \%$ for sensorineural symptoms and $19 \%$ for vascular symptoms among 58 workers with an average of 12 years of exposure to chipping hammers. Substantially lower prevalences were mentioned by Futatsuka $e t a l^{26}$ for 240 shipyard 
grinders in Japan (5\% white finger and $18 \%$ numbness) and by Starck et $a l^{27}$ for 171 shipyard platers, welders, and grinders exposed part time to vibration ( $5 \%$ white finger). In the present study of 271 workers the prevalences were $84 \%$ for sensorineural symptoms and $71 \%$ for vascular symptoms among full time grinders with average exposure duration of 11.3 years. It is likely that the high prevalence of symptoms found in the current study was due to the extremely specialised nature of job tasks within job categories such that "full-time grinders" used large abrasive grinders with high acceleration levels more than 32 hours per week on average.

The Stockholm Workshop scales proved useful in assessing symptom severity in this survey. In the only other published epidemiological study using the Stockholm Workshop vascular disease scale, Nilsson et $a l^{13}$ used it to stage a group of platers. The present study appears to be the first large epidemiological study of HAVS that has utilised both the vascular and sensorineural Stockholm Workshop scales as measures of health effect. Because no comparisons were made to quantitative tests, which presumably correspond more closely to abnormal pathophysiology than do symptoms alone, the present study cannot be considered a validation of the Stockholm Workshop scales. The strong exposure response relations found for both neurological and vascular symptoms, however, suggest that reported stage of disease may be related to progressive pathophysiological changes induced by vibration exposure. Additional study in which the Stockholm Workshop scale is compared with objective measurement of neurological and vascular function will permit more rigorous evaluation of the Stockholm Workshop scales as appropriate measures of disease.

There are several considerations involving potential bias in a cross sectional study. Firstly, because only $79 \%$ of the study participants returned questionnaires, it is possible that the prevalences of symptoms reported for the responders are biased estimates of the true prevalences among the entire population. Specifically, an overestimation of prevalence of symptoms would occur if diseased workers were more likely to complete and return the questionnaires than those who were free of disease. No information is available regarding the prevalence of disease among non-responders; therefore, the magnitude of this potential bias cannot be estimated. The prevalence of symptoms among the exposed workers, however, would remain greater than $\mathbf{5 0} \%$ even if all non-responders were disease free.

Twenty six responders (14 due to incomplete questionnaires and 12 due to potentially confounding medical conditions) were excluded from the data analysis. Excluding subjects from analysis due to medical conditions that cause symptoms similar to
HAVS would cause underestimation of the prevalence of disease if the conditions either occurred concommitantly with HAVS or represented misdiagnosed cases of HAVS.

Also, only active workers were studied; those who had left the workforce or were on disability at the time of the study were not solicited for participation. If workers left their jobs because of HAVS, then the results would cause an underestimation of the actual risk of developing HAVS. No estimates are available regarding the magnitude of a potential survivor effect in the present study.

It should also be noted that participants were not blind to their exposure state, nor to the purpose of the questionnaire, so symptoms were potentially overreported. The regularity of the relation between duration of exposure and reported symptoms, however, as well as the magnitude of the observed prevalences, argue that substantial disease occurs among this population. Further investigation with quantitative physiologically based methods will establish more objectively the prevalence of disease in this population.

Our attempts to relate symptoms to particular work practices were disappointing. It was not possible in this study to rank potential risk from use of specific types of vibratory tools. There was considerable covariance between total exposure to vibratory tools and use of specific tool types. The correlations found between different types of tools reflect the sampling strategy employed in the present study (that is, over-sampling of grinders, who use vibratory tools for much of their work time and use only some types of tools). On the other hand, the variable for working with tools held above head height more than five hours per week was significantly related to sensorineural stage classification. Although this variable was related to both exposure group and total number of hours of vibration exposure, it remained significantly related to sensorineural stage and vascular stage in logistic regression models that also included a term for cumulative exposure. This result suggests that symptoms might be reduced by restriction or modification of work requiring extensive overhead use of vibratory tools.

Three recent industrial hygiene studies at the shipyard provided observations on multiple tools, but produced little information that could be incorporated into a unitary quantitative exposure index. Considerable variability existed among measurements, and although there were differences in measurement strategy, such incongruity highlights the difficulty in integrating measurements from different experienced investigators. Some measurements were made under "simulated work" conditions, which may be useful for tool surveillance within a company but probably underestimate the accelerations experienced by workers during many of 
the work practices typical of this shipyard. The high accelerations reported by NIOSH, who measured tools under conditions approaching those of the uncontrolled worksite, may be more representative of the vibration to which workers in this shipyard are exposed. If American Conference of Governmental Industrial Hygienists (ACGIH) guidelines ${ }^{28}$ are applied to the accelerations for the tools used in this shipyard that are presented in table 2, chipping hammers, large burring machines, small burrs, and offset burrs would be banned outright. The commonly used large grinders would be restricted to under two hours of use per day, and only the offset wheel could be used for more than four hours per day. If more restrictive exposure criteria were considered, such as that advised by Saito ${ }^{29}$ not a single tool measured would be acceptable for more than episodic use. Interestingly, the observed unweighted accelerations are similar to those reported by Bovenzi $e t a l^{5}$ in their study of shipyard workers, along with a similar prevalence rate for reported sensorineural symptoms.

Vibration measurements presented in this paper highlight the problems associated with assessment of vibration exposure. Specifically, substantial variability is found when applying different techniques (for example, simulated $v$ actual job tasks) or even between different samples of the same tool. Also, selection of appropriate summary measures (weighted $v$ unweighted, truncated frequency range) remains controversial. ${ }^{30}$ The $\mathrm{NIOSH}$, recognising that these difficulties represent important practical barriers to the development of exposure based worker protection standards, has recommended in its recent criteria document for HAVS $^{2}$ a disease based surveillance standard.

In its criteria document on HAVS, NIOSH has recomended that workers with Stockholm Workshop scale stage 2 symptoms be removed from exposure sources until they return to Stage 0 . Such symptom based work removal may be a problematic approach to disease prevention. Firstly, there is evidence that most cases do not revert to stage 0 when they are removed from exposure, and those who do may take several years to recover. ${ }^{731}$ Therefore, symptom based removal (at least for stage 2) fails as a disease prevention strategy. Secondly, data from the current study indicate that most vibration exposed workers in the shipyard would be removed by their fifth year of work with vibratory tools. Thus, symptom-driven worker protection may not be realistic in the absence of exposure reduction. Finally, an imprecise relation exists between stage of symptom and measures of physiological abnormality. Several studies have suggested that vascular symptoms exceed corresponding abnormality in quantitative tests. ${ }^{32}{ }^{33}$ Conversely, affected workers with high thresholds for reporting of symptoms may therefore persist in their exposures and incur irreversible disease.

The most useful next step in defining the severity of vibration induced disease is to measure adverse health outcomes in an objective manner. Specifically, neurological function can be quantified using objective tests of sensory performance, ${ }^{15} 1734$ motor performance, ${ }^{1535}$ and peripheral nerve conduction. ${ }^{36}{ }^{37}$ Vascular disease can be quantified with finger plethysmography, ${ }^{3840}$ related measurements of blood pressure ${ }^{2341}$ and assessment of temperature regulation. ${ }^{42-44}$ These quantitative measures of physiology are not subject to recall and other biases potentially affecting the symptom outcomes on which the current staging system is based. Although medical monitoring coupled with removal seems an advisable approach, the effectiveness of particular quantitative measures for use as subclinical biological markers that predict subsequent disease remains to be demonstrated. In the absence of such information, reduction of generic exposure seems advisable.

This work was supported in part by a center grant from the US National Institute of Environmental Health Sciences to the Mount Sinai School of Medicine of the City University of New York (ES00928-15). We acknowledge the indispensable support of the Electric Boat Metal Trades Council, the Boilermakers' Union Local 614 who participated in the study, and $\mathrm{Mr}$ Michael Fitts in particular. Thanks are due Drs $\mathbf{R}$ Brubaker, $A$ Brammer, and $S$ Shalat for assistance in preparing the questionnaire used in the study.

Requests for reprints to: Richard Letz, $\mathrm{PhD}$, Division of Environmental and Occupational Health, Emory University School of Public Health, 1599 Clifton Road, Atlanta, GA 30329, USA.

1 Taylor W, Brammer AJ. Vibration effects on the hand and arm in industry: An introduction and review. In: Brammer AJ, Taylor W, eds. Vibration effects on the hand and arm in industry. New York: John Wiley \& Sons, 1982:1-12.

2 US National Institute for Occupational Safety and Health. Criteria for a recommended standard: occupational exposure to hand-arm vibration. Cincinnati: 1989. (DHHS 89-106.)

3 Hamilton A. A study of spastic anemia in the hands of stone cutters. US Bureau of Labor Statistics 1918;236:53.

4 Loriga G. Pneumatic tools: Occupation and Health. In: Encyclopedia of hygiene, pathology, and social welfare. Volume 2 Geneva: International Labour Organisation, 1934.

5 Cherniack MG. Raynaud's phenomenon of occupational origin Arch Intern Med 1990;150:519-22.

6 Riddle HFV, Taylor W. Vibraton-induced white finger among chain sawyers nine years after the introduction of anti-vibration measures. In: Brammer AJ, Taylor W, eds. Vibration effects on the hand and arm in industry. New York: John Wiley \& Sons, 1982:169-72.

7 Pyykkö I, Korhonen OS, Färkkilä MA, Starck JP, Aatola S, Jäntti V. Vibration syndrome among Finnish forest workers, a follow-up from 1972 to 1983. Scand J Work Environ Health 1986;12:307-12.

8 Futatsuka $M$, Ueno $T$. A follow-up study of vibration-induced white finger due to chain saw operation. Scand J Work Environ Health 1986;12:304-6. 
9 Brubaker RL, MacKenzie CJG, Hertzman C, Hutton SG, Slakov J. Longitudinal study of vibration-induced white finger among coastal fallers in British Columbia. Scand $J$ Work Environ Health 1987;13:305-8.

10 Taylor W, Pelmear PL. Vibration white finger in industry. London: Academic Press, 1975.

11 Brammer AJ, Taylor W, Lundborg G. Sensorineural stages of the hand-arm vibration syndrome. Scand $J$ Work Environ Health 1987;13:279-83.

12 Gemne G, Pyykkö I, Taylor W, Pelmear PL. The Stockholm Workshop scale for the classification of cold-induced Raynaud's phenomenon in the hand-arm vibration syndrome (revision of the Taylor-Pelmear scale). Scand J Work Environ Health 1987;13:275-8.

13 Nilsson T, Burström L, Hagberg $M$. Risk assessment of vibration exposure and white fingers among platers. Int Arch Occup Environ Health 1989;61:473-81.

14 Behrens V, Taylor W, Wilcox T, Miday R, Spaeth S, Burg J. Vibration syndrome in chipping and grinding workers: III. Epidemiology. J Occup Med 1984;26:769-73.

15 Cherniack MG, Letz R, Gerr F, Brammer A, Pace P. Detailed assessment of neurologic function in symptomatic shipyard workers. Br J Ind Med 1990;47:320-5.

16 NIOSH. Health Hazard Evaluation Report No HETA-3482011. Cincinnati: National Institute for Occupational Safety and Health, 1990.

17 Brammer AJ, Piercy JE, Auger PL. Assessment of impaired tactile sensation: A pilot study. Scand $J$ Work Environ Health 1987;13:380-4.

18 Ungar E. Data analysis of pneumatic tool vibration transmitted to the hands. Cambridge, Mass: Bolt, Beranak and Newman, 1987 (Project No 155453.)

19 Whitaker G. Vibratory measurement of pneumatic tools. Tempe, Arizona: BioTechnics Inc, 1988. (Project No 1-87717-888A.)

20 American National Standards Institute. Guide for the measurement and evaluation of human exposure to vibration transmitted to the hand. (S3.34). New York: ANSI, 1986.

21 SAS Institute. $S A S$ user's guide: statistics, Version 5. Cary NC: SAS Institute, 1985.

22 Harrell, FE. The LOGIST procedure. SUGI supplemental library user's guide. Version 5. Cary NC: SAS Institute, 1986.

23 Pyykkö I, Kolari P, Färkkilá MA, Starck JP, Korhonen OS, Jäntti V. Finger peripheral resistance during cold provocation in vasospastic disease. Scand J Work Environ Health 1986;12:35-9.

24 Brubaker RL, Mackenzie MD, Hutton SG. Vibration-induced white finger among selected underground rock drillers in British Columbia. Scand J Work Environ Health 1986;12: 296-300.

25 Bovenzi M, Petronio L, DiMario F. Epidemiological survey of shipyard workers exposed to hand-arm vibration. Int Arch Occup Environ Health 1980;46:251-66.

26 Futatsuka M, Sakurai T, Ariizumi M. Preliminary evaluation of dose-effect relationships for vibration induced white finger in Japan. Int Arch Occup Environ Health 1984;54:201-21.
27 Starck P, Pekkarinen J, Pyykkö I. Physical characteristics of vibration in relation to vibration-induced white finger. Am Ind Hyg Assoc J 1990;51:179-84.

28 American Conference of Governmental Industrial Hygienists 1990-91 threshold limit values for chemical substances and physical agents and biological exposure indices. Hand-arm (segmental) vibration. Cincinnati, Ohio: ACGIH, 1990:82-6.

29 Saito K. Prevention of the hand-arm vibration syndrome. Scand $J$ Work Environ Health 1987;13:301-4.

30 Pelmear PL, Leong D, Taylor W, Nagalingam M, Fung D. Measurement of vibration of hand-held tools: Weighted or unweighted? J Occup Med 1989;31:902-8.

31 Ekenvall L, Carlsson A. Vibration white finger: a follow up study. $\mathrm{Br} J$ Ind Med 1987;44:476-8.

32 Juul C, Nielsen SL. Locally induced digital vasospasm detected by delayed rewarming in Raynaud's phenomenon of occupational origin. $\mathrm{Br} J$ Ind Med 1981;38:78-90.

33 Thulesius O, Brubaker A, Berlin E. Response of digital blood pressure to cold provocation in cases with Raynaud's phenomenon. Angiology 1981;32:113-18.

34 Ekenvall L, Gemne G, Tegner R. Correspondence between neurological symptoms and outcome of quantitative sensory testing in the hand-arm vibration syndrome. $\mathrm{Br} J$ Ind $\mathrm{Med}$ 1989;46:570-4.

35 Färkkilä M, Aatola S, Starck J, Korhonen O, Pyykkö. Hand-grip force in lumberjacks: Two-year follow-up. Int Arch Occup Environ Health 186;58:203-8.

36 Araki S, Yokoyama K, Aono H, Murata K. Determination of the distributon of nerve conduction velocities in chain saw operators. Br J IndMed 1989;45:341-4.

37 Brammer AJ, Pyykkö. Vibration-induced neuropathy: Detection by nerve conduction measurements. Scand $J$ Work Environ Health 1987;13:317-22.

38 Bovenzi M. Vibration white finger, digital blood pressure, and some biochemical findings on workers operating tools in the engine manufacturing industry. $\mathrm{Am} J$ Ind Med 1988;14: 575-84.

39 Nielsen SL, Lassen NA. Measurement of digital blood pressure after local cooling. $J$ Appl Physiol 1977;43:907-10.

40 Olsen N, Nielsen SL. Diagnosis of Raynaud's phenomenon in quarrymen's traumatic vasospastic disease. Scand J Work Environ Health 1979;5:249-56.

41 Pyykkö I, Hyvärinen J. Vibration induced changes of sympathetic vasomotor tone. Acta Chir Scand Suppl 1976;465:23-6.

42 Bovenzi M. Finger-thermometry in the assessment of subjects with vibration-induced white finger. Scand $J$ Work Environ Health 1987;13:348-51.

43 Pelmear PL, Roos J, Leong D, Wong L. Cold provocation test results from a 1985 survey of hard-rock miners in Ontario. Scand $J$ Work Environ Health 1987;13:343-7.

44 Welch CL. Digital rewarming time in the assessment of vibration induced white finger. Scand $J$ Work Environ Health $1986 ; 12: 249-50$.

Accepted 13 May 1991. 